Article

\title{
Levels of Alternaria Toxins in Selected Food Commodities Including Green Coffee
}

\author{
Claudia Mujahid ${ }^{1}$, Marie-Claude Savoy ${ }^{1}$, Quentin Baslé ${ }^{2}$, Pei Mun Woo ${ }^{2}$, Edith Chin Yean Ee ${ }^{2}$, \\ Pascal Mottier ${ }^{1}$ and Thomas Bessaire ${ }^{1, * \mathbb{D}}$ \\ 1 Nestlé Research, Route du Jorat 57, Vers-chez-les-Blanc, 1000 Lausanne, Switzerland; \\ claudia.mujahid@rdls.nestle.com (C.M.); marieclaude.savoy@rd.nestle.com (M.-C.S.); \\ pascal.mottier@rdls.nestle.com (P.M.) \\ 2 Nestlé Quality Assurance Center, 29 Quality Road, Singapore 618802, Singapore; \\ Quentin.Basle@rdsg.nestle.com (Q.B.); PeiMun.Woo@rdsg.nestle.com (P.M.W.); \\ EdithChinYean.Ee@rdsg.nestle.com (E.C.Y.E.) \\ * Correspondence: thomas.bessaire@rdls.nestle.com; Tel.: +41-21-785-8323
}

Received: 19 August 2020; Accepted: 10 September 2020; Published: 15 September 2020

\begin{abstract}
Alternaria toxins are emerging mycotoxins, candidates for regulation by European Authorities. Therefore, highly sensitive, confirmatory, and reliable analytical methodologies are required for their monitoring in food. In that context, an isotope dilution LC-MS/MS method was developed for the analysis of five Alternaria toxins (Altenuene, Alternariol, Alternariol monomethylether, Tentoxin, and Tenuazonic Acid) in a broad range of commodities including cereals and cereal-based products, tomato-based products, tree nuts, vegetable oils, dried fruits, cocoa, green coffee, spices, herbs, and tea. Validation data collected in two different laboratories demonstrated the robustness of the method. Underestimation of Tenuazonic Acid level in dry samples such as cereals was reported when inappropriate extraction solvent mixtures were used as currently done in several published methodologies. An investigation survey performed on 216 food items evidenced large variations of Alternaria toxins levels, in line with data reported in the last EFSA safety assessment. The analysis of 78 green coffee samples collected from 21 producing countries demonstrated that coffee is a negligible source of exposure to Alternaria toxins. Its wide scope of application, adequate sample throughput, and high sensitivity make this method fit for purpose for the regular monitoring of Alternaria toxins in foods.
\end{abstract}

Keywords: mycotoxins; Alternaria toxins; LC-MS/MS; isotopic dilution; compliance; tenuazonic acid; risk assessment

Key Contribution: Validation data collected by two laboratories demonstrated that the analytical method is suitable for the monitoring of five Alternaria toxins in a broad range of food commodities. Human exposure to Alternaria toxins through coffee consumption was found negligible and is not expected to represent a safety concern.

\section{Introduction}

The ability of fungi to produce mycotoxins is largely influenced by temperature, rainfalls, relative humidity, and stress conditions in the plants. Mycotoxins are therefore one of the most severe food safety hazards amplified by global climate change, which may facilitate appearance and dissemination of new toxins, the so-called "emerging mycotoxins" [1]. Among them, Alternaria toxins are secondary metabolites produced by Alternaria fungal species, most commonly Alternaria alternata but also Alternaria tenuissima and Alternaria infectoria. As pathogens, they affect many crops including grains, 
oil seeds, spices, and various fruits and vegetables, and may thus enter the food chain. Due to their growth even at low temperature, Alternaria fungal species are also responsible for spoilage of commodities during refrigerated transport and storage [2-4].

Alternaria fungal species produce more than 70 toxins but only a small number of them have been chemically characterized so far [5]. They exhibit broad structure divergence and are commonly divided into five different classes. Some toxins such as alternariol $(\mathrm{AOH})$, alternariol monomethyl ether (AME), tenuazonic acid (TeA), and altertoxins were described to induce harmful effects in animals, including fetotoxic and teratogenic effects. Culture extracts of A. alternata but also AOH and AME were found mutagenic and clastogenic in various in vitro systems [2,3]. Considering their possible harmful effects, presence of these toxins in food may be considered as a serious threat to public health.

These findings prompted the European Food Safety Agency (EFSA) to publish a first risk assessment on Alternaria toxins (TeA, AME, AOH, Tentoxin (TEN), and Altenuene (ALT)) in feed and food in 2011 [3]. Due to the lack of toxicity data available, the expert panel could not establish health-based guidance values and used the threshold of toxicity concern (TTC) for risk assessment. The TTC concept holds that the presence of a chemical in food does not represent a safety concern even in absence of toxicological data, provided exposure remains below the TTC of the pertinent structural class $[3,6]$. Based on the limited analytical data available at that time, the estimated mean chronic dietary exposures exceeded TTC values for the two genotoxic compounds AOH and AME. A dietary exposure assessment to Alternaria toxins in the European population was then published 5 years later [4], using thousands of data generated during the 2010-2015 period [7]. Interestingly, higher exposures were estimated compared to those estimated in 2011, and highest levels were reported for TeA with tomato-based products, tree nuts, oil seeds, grains, and fruits being the most contaminated commodities. It was also noted that infants were the population group with the highest dietary exposure. EFSA still recommended to develop sensitive analytical methods to allow quantification at low levels (avoiding too many left-censored data) and to generate more analytical data in foodstuffs.

In this context, various methodologies and studies on Alternaria toxins in foods and drinks have been published over the last years, e.g., in tomato-based products, fruit and vegetable-based products, wine [5,8], grapes [9], tea and herbal infusions [10], dried figs, olives, sunflower seeds and cereals [11], wolfberry [12], drinking water [13]. A study from the Technical University of Munich [14] has showed that infant cereals and baby food purees purchased from German supermarkets were frequently contaminated with Alternaria toxins. AME, TEN, and TeA were found in more than $80 \%$ of the samples at levels up to 1.4 (AME), 7.5 (TEN), and $221 \mu \mathrm{g} / \mathrm{kg}$ (TeA). In the latest study by Gambacorta, et al. [15], a large proportion of the 94 spices and 37 herbs analyzed were found contaminated with several Alternaria toxins. TeA was the predominant mycotoxin with the highest percentages of positive samples (76\%), followed by AME (46\%), TEN (37\%), AOH (34\%), and ALT (5\%) with maximum levels up to $106,793,306,179,636$, and $22 \mu \mathrm{g} / \mathrm{kg}$, respectively. The EFSA database and recent scientific publications did not identify coffee beans as a significant target of Alternaria contamination. Occurrence of these toxins in green coffee was investigated in one single study in which low levels of AOH and AME were reported [16]. However, ALT and TeA were not considered for analysis.

No regulation applies for Alternaria toxins in foodstuffs yet, but maximum levels are currently under consideration by the European Commission [17]. In June 2019, a draft EU Commission Recommendation on the monitoring of three Alternaria toxins (AOH, AME, TeA) in food was issued which included benchmark values above which investigations by Food Business Operators would be appropriate to identify the factors resulting in high levels in certain foods [18]. Benchmark values in processed tomato products, sesame seeds, sunflower seeds, sunflower oil, but also in cereal-based foods for infants and young children, were set at levels ranging from 5 to $30 \mu \mathrm{g} / \mathrm{kg}$ (AOH, AME) and 100-500 $\mu \mathrm{g} / \mathrm{kg}$ (TeA). Benchmark levels were set as well for TeA in tree nuts $(100 \mu \mathrm{g} / \mathrm{kg})$, dried fruits $(1000 \mu \mathrm{g} / \mathrm{kg})$, and paprika powder $(10,000 \mu \mathrm{g} / \mathrm{kg})$. As stated in the draft document, these benchmark values do not represent safe levels in food. 
Therefore, there is a need for reliable analytical methodologies applicable to a broad range of food commodities. In that context, the European Commission Joint Research Centre (JRC, Geel, Belgium), which was the EU Reference Laboratory for Mycotoxins at that time, organized a Multi Laboratory Test (MLT) in 2018 to support a LC-MS/MS method standardization by the European Committee for Standardization $[19,20]$. Although limited to the analysis of tomato purees, wheat flour, and sunflower seeds, its analyte scope (AOH, AME, TeA, TEN, and ALT) and quantification approach (isotope dilution) made this confirmatory method a good candidate for deployment in high routine environments, facing today a broad range of items to monitor, an increasing pressure to shorten turn-around time, and cost constraints [21]. Already published methodologies did not match with these expectations due to (a) limited number of food items considered [20], (b) limited analyte scope missing important Alternaria toxin(s) [11], (c) cumbersome sample extraction [14], or (d) quantification approach hardly workable for "multi-matrix" analytical method [8,15,22-24].

Consequently, the method validated during the MLT was tentatively extended to a broader range of food commodities including all the 'EU benchmarked foods'. The present study describes the modifications that were brought to circumvent the analytical issues observed. Extensive validation data collected in two different laboratories are presented to demonstrate method robustness. This study also aims to provide additional data to get a reliable picture of the occurrence of Alternaria toxins in common foods including green coffee for which analytical data are scarce. A risk assessment was further performed to evaluate whether coffee could be a significant source of exposure to Alternaria toxins.

\section{Results and Discussion}

\subsection{Analytical Method Development}

\subsubsection{LC-MS/MS Conditions}

Detection of the five Alternaria toxins were first evaluated using either positive or negative electrospray ionization modes. $\mathrm{AOH}, \mathrm{AME}$, and TeA exhibited a predominant deprotonated molecular ion $[\mathrm{M}-\mathrm{H}]^{-}$whereas TEN and ALT were seen either as $[\mathrm{M}+\mathrm{H}]^{+}$or $[\mathrm{M}-\mathrm{H}]^{-}$species. To avoid the use of polarity switching that may hamper method performances when using older LC-MS instruments, the negative ionization mode was exclusively selected as done previously [20]. Collision-induced dissociation (CID) mass spectra of each precursor were then recorded at various collision energies before selecting the optimal fragment ions, MS/MS transition reactions, and related instrument parameters. MRM transition reactions of each internal standard (IS) were the ones corresponding to the related native toxin taking into account the degree of isotope labeling. Adequate LC separation of the five Alternaria toxins was attained with a classical Waters Acquity BEH C18 column employing a 11-min LC gradient in alkaline conditions as done in other studies [5,8,20,21,23]. Mobile phases were ammonium acetate $(5 \mathrm{mM})$ in water $\mathrm{pH} 8$ and methanol. TeA (the most polar compound) eluted at retention time $2.0 \mathrm{~min}$, comfortably longer than the void volume of the column, followed by ALT, AOH, TEN, and AME at 3.5, 3.8, 4.3, and $5.0 \mathrm{~min}$, respectively.

\subsubsection{Sample Preparation}

Alternaria toxins were initially extracted following an analytical procedure (namely MLT method) evaluated in 2018 during a JRC intercollaborative study. Briefly, wheat flour, tomato puree, and sunflower seeds were extracted with a methanol/water/acetic acid (85/14/1, v/v/v) mixture, and the extracts subsequently purified on a polymeric solid-phase extraction (SPE). To point out that a large proportion of organic solvent is used in such extraction medium (i.e., 85\% in that case), a fact recurrently noticed in other published methodologies, e.g., methanol/water $(80 / 20, v / v,[20])$, acetonitrile/water/formic acid (80/20/0.1, v/v/v, [8] or 84/16/1, v/v/v, [11]), methanol/water/acetic acid $(79 / 20 / 1, v / v / v,[23])$. 
Applicability of the QuEChERS (Quick, Easy, Cheap, Efficient, Rugged and Safe) approach for the analysis of Alternaria toxins was considered in parallel since already validated elsewhere $[8,9,25]$. This approach is faster, user friendly, cost efficient, and already used in many laboratories dealing with chemical contaminants analysis, e.g., mycotoxins, veterinary drugs, pesticides [26-29]. Our protocol encompasses an initial extraction of the analytes with a mixture of water, acetonitrile, and formic acid $(50 / 50 / 0.1, v / v / v)$, followed by a liquid-liquid partition using salt mixtures.

Both MLT and QuEChERS approaches were compared using fortified tomato purees, sunflower seeds, and cereal samples but also incurred commodities (cereals). Similar results were obtained for ALT, AOH, AME, and TEN. Surprisingly, underestimation of TeA level was observed using the MLT method applied for dry incurred matrices (e.g., cereals), but not for high-water content samples (e.g., tomato puree) or in fortified samples, these latter generally used to mimic natural contamination during method validation and/or quality control plans. Recovery of the related labeled internal standard (IS) ${ }^{13} \mathrm{C}_{2}$-TeA spiked on the test portion at the beginning of the procedure was around $80 \%$ by both methods demonstrating that no matrix effects occurred and that the overall extraction of the IS worked well. In our hands, these data suggested that discrepancies between both approaches originated from the extractability of the native TeA toxin.

The impact of water content in the extraction mixture was thus investigated using a cereal-based product (mix of seven cereals: rice, millet, spelt, oat, rye, barley, and corn) and a rice flour, both known to contain 'natural' levels of TeA. Samples were extracted with mixtures containing either acidified methanol or acetonitrile, each with different amounts of water. Extracts were first thoroughly shaken, diluted, then centrifuged, and subsequently injected into the LC-MS/MS. As shown in Figure 1, an incomplete extraction of the native TeA toxin was observed when extraction mixtures contained only $15 \%$ of water, as considered in the MLT method. These data strongly suggest that TeA, the most frequently detected Alternaria toxin, needs a certain amount of water to be efficiently extracted from incurred dry samples.
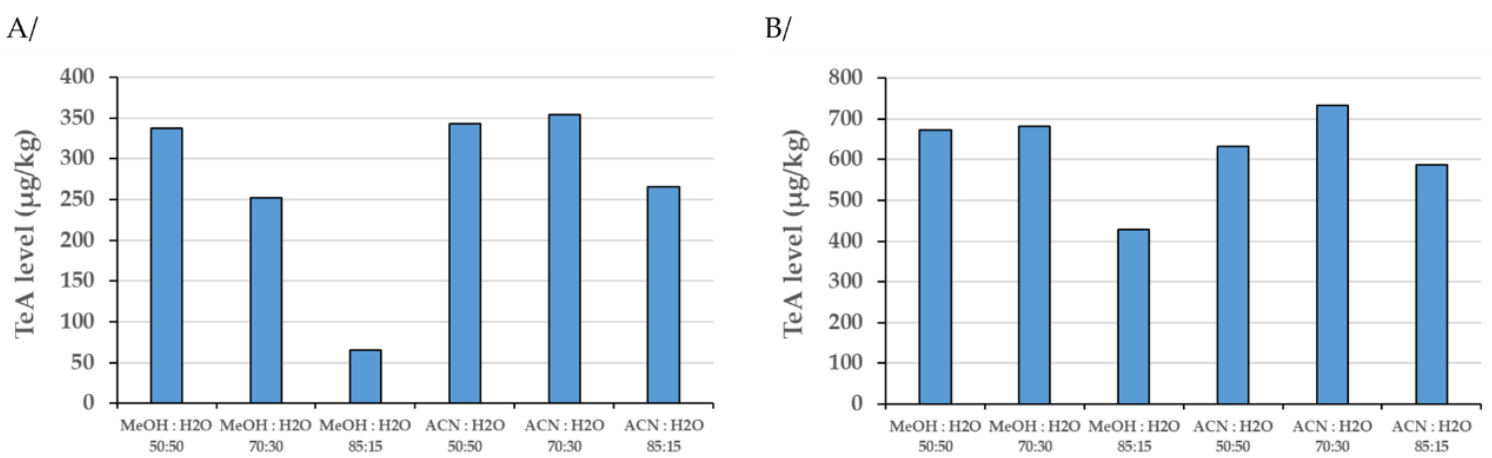

Figure 1. Impact of the water content in extraction mixtures on tenuazonic acid (TeA) levels in incurred samples ((A) breakfast cereal; (B) rice flour). All extraction mixtures were supplemented with $0.1 \%$ formic acid.

Historically, most methods for monitoring Alternaria toxins were devoted to the analysis of high-water content commodities such as tomatoes and tomato-based products and fruit juices $[24,25,30,31]$. In that case, the low amount of water in the extraction mixture might be compensated by the natural water content of the matrix. However, an efficient method for such monitoring should be applicable to a broad range of foods whatever their water content, this with the goal to fulfill EFSA recommendations for data collection. In that context, our initial findings prompted us to favor the development of a "multi-matrix" QuEChERS-based method rather than an extension of the MLT method to other matrices.

Optimization of the QuEChERS approach was conducted using samples known to be challenging when analyzed by LC-MS/MS, e.g., green coffee and spices, due to strong signal suppression (i.e., matrix effects). Best results were obtained using $\mathrm{Na}_{2} \mathrm{SO}_{4} / \mathrm{NaCl}(4 \mathrm{~g}+1 \mathrm{~g})$ salts to induce liquid-liquid partition 
and hexane to remove co-extracted fat as a subsequent clean-up step. This clean-up procedure is extensively used for mycotoxins and tropane alkaloids analyses in Nestlé laboratories [26,28,32]. To reduce the strong matrix effects observed for ALT and $\mathrm{AOH}$ in some matrices, smaller test portions were considered for tree nuts, dried fruits, green coffee, cocoa, tomato-based products, and vegetable oils (2.5 g) and for spices, herbs, and tea ( $0.5 \mathrm{~g})$.

Quantification was finally conducted by isotopic dilution using labeled isotopomers for each of the five Alternaria toxins as internal standards.

\subsection{Method Performance Characteristics}

The method was first validated by Laboratory 1 (Switzerland) for cereals and cereal-based products, tomato-based products, and spices at two fortification levels and for tree nuts, vegetable oils, and dried fruits at a single fortification level using a sample representative of each commodity group. The five solvent-based calibration curves followed a linear model with $\mathrm{r}^{2}>0.99$ over the $0-100 \mathrm{ng} / \mathrm{mL}$ range $(0-500 \mathrm{ng} / \mathrm{mL}$ for TeA). Deviations of back-calculated concentrations of calibrants standards from the true concentration were never out $\pm 20 \%$, as requested by SANTE/12682/2019 document [33].

As shown in Tables 1 and 2, analytical performance data were $\operatorname{RSD}(\mathrm{r})<12 \%, \operatorname{RSD}(\mathrm{iR})<15 \%$ and recoveries ranging from $89 \%$ to $112 \%$ regardless of the toxin/matrix/fortification levels, thus fulfilling SANTE/12682/2019 requirements [33]. Only TeA precision data in spices were slightly higher due to the unavailability of TeA-free paprika powder samples. Although the lowest TeA content sample was selected for validation purpose, performance data generated at the $1250 \mu \mathrm{g} / \mathrm{kg}$ spiking level (RSD(r): $26 \%$ and RSD(iR): $29 \%$ ) were still impacted by the native TeA content (4500 $\mu \mathrm{g} / \mathrm{kg})$ of this item. This precluded the collection of validation data at low level (i.e., $50 \mu \mathrm{g} / \mathrm{kg}$ ) in this commodity in Laboratory 1. Interestingly, this incurred paprika powder was also analyzed as such (i.e., without fortification) in duplicate over 6 days leading to RSD(r) and RSD(iR) values at 3.7\% and 2.9\%, respectively, evidencing the low test portion size $(0.5 \mathrm{~g})$ as sufficiently representative when dealing with such powdered sample. Applicability of the method to other food commodities was further demonstrated by analyzing additional samples in duplicate, each after fortification, e.g., at $0.5 \mu \mathrm{g} / \mathrm{kg}$ for green coffee $(2.5 \mu \mathrm{g} / \mathrm{kg}$ for TeA), at $2 \mu \mathrm{g} / \mathrm{kg}$ for cocoa powder (10 $\mu \mathrm{g} / \mathrm{kg}$ for TeA), and $10 \mu \mathrm{g} / \mathrm{kg}$ for tea and herbs $(50 \mu \mathrm{g} / \mathrm{kg}$ for TeA). Differences between duplicates were $<20 \%$ and recovery data ranged from $75 \%$ to $119 \%$.

Table 1. Limits of quantification (LOQs) of the five Alternaria toxins in various food commodities.

\begin{tabular}{ccc}
\hline Food Commodity & Analyte & LOQ $(\mu \mathrm{g} / \mathbf{k g})$ \\
\hline Cereals and cereal-based products, \\
green coffee & ALT, AOH, AME, TEN & 0.5 \\
Tree nuts, dried fruits, cocoa, vegetable oil, tomato-based products & ALT, AOH, AME, TEN & 2.5 \\
\hline \multirow{2}{*}{ Spices, herbs, tea } & TeA & 10 \\
\hline & ALT, AOH, AME, TEN & 10 \\
\hline
\end{tabular}

Performance parameters including sensitivity, precision, and recovery were then further confirmed by Laboratory 2 (Singapore), ultimately demonstrating ruggedness of the method.

Limits of quantification (LOQs) were arbitrarily set for each matrix/toxin combination at the lowest validated levels and ranged from 0.5 to $10 \mu \mathrm{g} / \mathrm{kg}$ for ALT, AOH, AME, and TEN and from 2.5 to $50 \mu \mathrm{g} / \mathrm{kg}$ for TeA (Table 1). 
Table 2. Method performance characteristics obtained by Laboratory 1 (Switzerland) and Laboratory 2 (Singapore).

\begin{tabular}{|c|c|c|c|c|c|c|c|}
\hline Sample & Lab & Analyte & $\begin{array}{c}\text { Fortification } \\
\text { Level }(\mu \mathrm{g} / \mathrm{kg})\end{array}$ & $\underset{(\%)}{\operatorname{RSD}_{\mathrm{r}}}$ & $\underset{(\%)}{\mathrm{RSD}_{\mathrm{IR}}}$ & $\begin{array}{c}\text { Recovery } \\
(\%)\end{array}$ & $\begin{array}{c}\text { Measurement } \\
\text { Uncertainty }(\%)\end{array}$ \\
\hline \multirow{15}{*}{$\begin{array}{l}\text { Cereal-based } \\
\text { products }\end{array}$} & \multirow{10}{*}{ Lab 1} & \multirow{2}{*}{ ALT } & 0.5 & 3.4 & 5.8 & 104 & 12 \\
\hline & & & 25 & 0.3 & 4.4 & 95 & 11 \\
\hline & & \multirow{2}{*}{$\mathrm{AOH}$} & 0.5 & 4.3 & 12 & 110 & 25 \\
\hline & & & 25 & 1.7 & 3.9 & 97 & 8.4 \\
\hline & & \multirow{2}{*}{ AME } & 0.5 & 1.2 & 4.5 & 104 & 9.6 \\
\hline & & & 25 & 0.6 & 9.1 & 91 & 22 \\
\hline & & \multirow{2}{*}{ TEN } & 0.5 & 5.0 & 3.7 & 100 & 7.4 \\
\hline & & & 25 & 1.0 & 1.4 & 97 & 4.2 \\
\hline & & \multirow{2}{*}{$\mathrm{TeA}$} & 2.5 & 5.7 & 6.8 & 109 & 16 \\
\hline & & & 125 & 0.4 & 1.1 & 105 & 5.2 \\
\hline & & ALT & 0.5 & 5.5 & 13.0 & 96 & 28 \\
\hline & & $\mathrm{AOH}$ & 0.5 & 3.3 & 12.7 & 96 & 27 \\
\hline & Lab 2 & AME & 0.5 & 6.7 & 14.7 & 95 & 31 \\
\hline & & TEN & 0.5 & 5.3 & 6.6 & 100 & 14 \\
\hline & & $\mathrm{TeA}$ & 2.5 & 2.5 & 5.3 & 101 & 11 \\
\hline \multirow{15}{*}{$\begin{array}{l}\text { Tomato-based } \\
\text { products }\end{array}$} & \multirow{10}{*}{ Lab 1} & \multirow{2}{*}{ ALT } & 2 & 5.1 & 6.1 & 102 & 13 \\
\hline & & & 50 & 2.8 & 7.8 & 94 & 17 \\
\hline & & \multirow{2}{*}{$\mathrm{AOH}$} & 2 & 7.2 & 9.5 & 102 & 20 \\
\hline & & & 50 & 2.8 & 2.9 & 94 & 8.7 \\
\hline & & \multirow{2}{*}{ AME } & 2 & 1.9 & 3.5 & 101 & 7.6 \\
\hline & & & 50 & 0.6 & 6.3 & 89 & 18 \\
\hline & & \multirow{2}{*}{ TEN } & 2 & 1.2 & 2.0 & 99 & 4.2 \\
\hline & & & 50 & 0.8 & 0.8 & 96 & 4.0 \\
\hline & & & 10 & 5.2 & 8.4 & 102 & 18 \\
\hline & & $\mathrm{TeA}$ & 250 & 0.3 & 1.4 & 97 & 4.5 \\
\hline & & ALT & 2 & 4.8 & 6.4 & 98 & 14 \\
\hline & & $\mathrm{AOH}$ & 2 & 4.5 & 6.5 & 99 & 14 \\
\hline & Lab 2 & AME & 2 & 1.2 & 3.1 & 109 & 10 \\
\hline & & TEN & 2 & 2.1 & 1.9 & 110 & 10 \\
\hline & & $\mathrm{TeA}$ & 10 & 7.7 & 12 & 106 & 26 \\
\hline & & & 10 & 6.6 & 6.0 & 100 & 12 \\
\hline & & ALI & 250 & 2.3 & 4.4 & 90 & 15 \\
\hline & & & 10 & 7.9 & 12 & 101 & 25 \\
\hline & & $\mathrm{AOH}$ & 250 & 4.6 & 7.8 & 93 & 18 \\
\hline & Lab 1 & & 10 & 3.2 & 15 & 106 & 32 \\
\hline & & AME & 250 & 0.9 & 3.5 & 94 & 10 \\
\hline Spices & & & 10 & 2.4 & 2.4 & 110 & 10 \\
\hline & & TEN & 250 & 1.1 & 1.1 & 97 & 3.5 \\
\hline & & $\mathrm{TeA}$ & 1250 & 26 & 29 & 91 & 58 \\
\hline & & ALT & 10 & 7.2 & 16 & 98 & 34 \\
\hline & & $\mathrm{AOH}$ & 10 & 3.9 & 5.6 & 98 & 12 \\
\hline & Lab 2 & AME & 10 & 1.4 & 4.4 & 113 & 15 \\
\hline & & TEN & 10 & 3.1 & 4.0 & 115 & 16 \\
\hline & & $\mathrm{TeA}$ & 50 & 19 & 19 & 100 & 40 \\
\hline & & ALT & 2 & 4.7 & 3.9 & 102 & 8.3 \\
\hline & & $\mathrm{AOH}$ & 2 & 3.2 & 3.3 & 102 & 7.0 \\
\hline & Lab 1 & AME & 2 & 1.5 & 2.8 & 102 & 5.9 \\
\hline & & TEN & 2 & 1.4 & 2.1 & 98 & 4.4 \\
\hline Sunflower oil & & $\mathrm{TeA}$ & 10 & 1.7 & 2.4 & 103 & 5.8 \\
\hline & & ALT & 2 & 2.4 & 4.9 & 98 & 10 \\
\hline & & $\mathrm{AOH}$ & 2 & 3.3 & 4.7 & 95 & 11 \\
\hline & Lab 2 & AME & 2 & 1.1 & 9.9 & 92 & 21 \\
\hline & & TEN & 2 & 2.4 & 2.5 & 100 & 5.1 \\
\hline & & $\mathrm{TeA}$ & 10 & 1.0 & 1.4 & 97 & 4.2 \\
\hline & & ALT & 2 & 4.1 & 11 & 92 & 23 \\
\hline & & $\mathrm{AOH}$ & 2 & 12 & 11 & 106 & 23 \\
\hline Dried fruits & Lab 1 & AME & 2 & 2.2 & 3.5 & 94 & 9.9 \\
\hline & & TEN & 2 & 1.7 & 3.0 & 103 & 6.4 \\
\hline & & $\mathrm{TeA}$ & 10 & 2.9 & 3.2 & 95 & 8.7 \\
\hline & & ALT & 2 & 6.3 & 8.4 & 106 & 18 \\
\hline & & $\mathrm{AOH}$ & 2 & 7.8 & 7.3 & 95 & 16 \\
\hline Tree nuts & Lab 1 & AME & 2 & 2.0 & 7.4 & 101 & 16 \\
\hline & & TEN & 2 & 1.6 & 1.9 & 103 & 4.7 \\
\hline & & $\mathrm{TeA}$ & 10 & 5.7 & 5.3 & 112 & 15 \\
\hline
\end{tabular}


Over time, stability of toxin standards in solutions is key information which is systematically challenged during accreditation and GLP assessment audits. Both labeled and unlabeled stock standards solutions stored in the freezer at $-20^{\circ} \mathrm{C}$ were thus compared one year later against freshly prepared ones within the same analytical sequences i.e., under repeatability conditions to circumvent inherent day-to-day variations of mass spectrometry measurements. All stock solutions $(100 \mu \mathrm{g} / \mathrm{mL}$ in methanol $)$ were found stable for at least one year. As well, sample extracts were found stable for up to 4 days after extraction when stored in the fridge at $4{ }^{\circ} \mathrm{C}$ or in the autosampler cooled down at max $8{ }^{\circ} \mathrm{C}$. Such information is valuable, typically when the extracted solutions need to be reinjected in case of instrument shutdown, aborted sequence, etc.

\subsection{Occurrence of Alternaria Toxins in Various Food Commodities}

A summary of Alternaria toxins levels found in each sample category (corresponding to 138 samples in total) is given in Table 3 Individual data along with sample details are available in Table S1.

Table 3. Occurrence of Alternaria toxins in 138 food items. Ranges of concentrations are given in $\mu \mathrm{g} / \mathrm{kg}$ (nb of positives).

\begin{tabular}{cccccc}
\hline Foods (Nb of Samples) & ALT & AOH & AME & TEN & TeA \\
\hline Cereals (31) & $<0.5(0)$ & $<0.5-11.8(8)$ & $<0.5-3.4(6)$ & $<0.5-31.2(9)$ & $<2.5-766(25)$ \\
Cereal-based products (15) & $<0.5(0)$ & $<0.5-7.4(4)$ & $<0.5-2.7(3)$ & $<0.5-6.9(10)$ & $<2.5-628(11)$ \\
Cocoa (5) & $<2(0)$ & $<2(0)$ & $<2(0)$ & $<2(0)$ & $<10(0)$ \\
Fruits, dried and juice (9) & $<2-17.2(1)$ & $<2-80.2(3)$ & $<2-47.8(2)$ & $<2-13.4(1)$ & $<10-685(7)$ \\
Herbs (11) & $<10(0)$ & $<10-111(6)$ & $<10-25.6(4)$ & $<10-113(5)$ & $<50-748(10)$ \\
Nuts (13) & $<2(0)$ & $<2-6.4(4)$ & $<2-3.5(2)$ & $<2(0)$ & $<10-62.0(4)$ \\
Sunflower oil (4) & $<2(0)$ & $<2(0)$ & $<2-2.4(1)$ & $<2-3.9(1)$ & $<10(0)$ \\
Spices (21) & $<10(0)$ & $<10-153(13)$ & $<10-73.6(10)$ & $<10-73.4(13)$ & $<50-20,478(19)$ \\
Tea (15) & $<10(0)$ & $<10(0)$ & $<10(0)$ & $<10(0)$ & $<50(0)$ \\
Vegetables incl. tomato (14) & $<2(0)$ & $<2-65.3(7)$ & $<2-7.9(1)$ & $<2-3.1(2)$ & $<10-1096(11)$ \\
\hline
\end{tabular}

Spices $(n=21)$ analyzed were caraway, coriander, garlic, chili, cayenne pepper, and paprika. EU benchmark level has been set only for TeA in paprika powder at 10,000 $\mu \mathrm{g} / \mathrm{kg}$. In our survey, only one paprika powder (TeA $7356 \mu \mathrm{g} / \mathrm{kg}$ ) over the eight analyzed was found below this benchmark level (concentrations in outliers: $10,163-18,856 \mu \mathrm{g} / \mathrm{kg}$ ). Chili items were found quite contaminated by $\mathrm{TeA}$ as well, with concentrations ranging from 4510-20,478 $\mu \mathrm{g} / \mathrm{kg}$. Co-occurrence of several Alternaria toxins (but not ALT) was frequently observed in this ingredient category, and at the highest concentrations found in this survey (exception was garlic in which none of the toxins were detected).

Herbs $(n=11)$ were marjoram, oregano, and thyme. Again, TeA was found in all items (but one) at levels up to $748 \mu \mathrm{g} / \mathrm{kg}$, and ALT was not detected at all. Other toxins ranged within the $<10-113 \mu \mathrm{g} / \mathrm{kg}$ concentration range. Such high concentrations of Alternaria toxins in spices and herbs are aligned with data reported in a recent publication [15].

Levels of Alternaria toxins in sunflower oils $(n=4)$ were all below the EU benchmark levels set for this material, which are $10 \mu \mathrm{g} / \mathrm{kg}$ for $\mathrm{AOH}, 10 \mu \mathrm{g} / \mathrm{kg}$ for AME, and $100 \mu \mathrm{g} / \mathrm{kg}$ for TeA. TEN (not a benchmarked toxin) was detected in one sample at $3.9 \mu \mathrm{g} / \mathrm{kg}$, and AME in another one at $2.4 \mu \mathrm{g} / \mathrm{kg}$. Recently, 16 different sunflower oil samples were analyzed, and only TeA and TEN were detected (in one and three samples, respectively) at levels $<10 \mu \mathrm{g} / \mathrm{kg}$ [20]. In another study [23], TeA was detected in $31 \%$ of 39 sunflower oils at level up to $458 \mu \mathrm{g} / \mathrm{kg}$ (mean of positive values $163 \mu \mathrm{g} / \mathrm{kg}$ ). The authors reported that cold-pressed sunflower seed oils showed significantly higher Alternaria toxins contaminations compared to refined products. Interestingly, all these studies highlighted TEN to be the most prevalent toxin in sunflower seed oils, albeit quantified at low levels $(<10 \mu \mathrm{g} / \mathrm{kg})$.

Tree nuts $(n=13)$ comprised almonds, hazelnuts, peanuts, and pistachio. A benchmark level at $100 \mu \mathrm{g} / \mathrm{kg}$ for TeA has been set for this food category. None of the samples under survey reached this 
value (highest level was $62 \mu \mathrm{g} / \mathrm{kg}$ ). Other toxins (with the exception ALT) were sporadically detected $(<2-6.4 \mu \mathrm{g} / \mathrm{kg})$.

Vegetables $(n=14)$ were carrot and pea (processed ingredients), and tomato-based products (powder, pulped, sauce, etc.). Only 'processed tomato products' is mentioned in the EU draft document with limits set at $10 \mu \mathrm{g} / \mathrm{kg}$ for AOH, $5 \mu \mathrm{g} / \mathrm{kg}$ for AME, and $500 \mu \mathrm{g} / \mathrm{kg}$ for TeA. Two tomato products were found 'not compliant' in regard to these benchmark levels: one containing $\mathrm{AOH}(13.7 \mu \mathrm{g} / \mathrm{kg})$ and $\mathrm{TeA}(641 \mu \mathrm{g} / \mathrm{kg})$, and the second containing AOH $(65.3 \mu \mathrm{g} / \mathrm{kg}), \operatorname{AME}(7.9 \mu \mathrm{g} / \mathrm{kg})$, and TeA $(1096 \mu \mathrm{g} / \mathrm{kg})$. Occurrences of high levels of TeA in fresh and dried tomatoes in Italy have been recently reported [34].

Cereals $(n=31)$ surveyed were corn, barley, millet, oat, rice, rye, rapeseed meal, sorghum, soya, spelt, and wheat. TeA was evidenced in most items at levels ranging from 3.5 to $766 \mu \mathrm{g} / \mathrm{kg}$. Highest levels were observed in a rice flour $(758 \mu \mathrm{g} / \mathrm{kg}$ ) and two rapeseed meal samples (766 and $636 \mu \mathrm{g} / \mathrm{kg}$ ). Other Alternaria toxins, with the exception of ALT, were sporadically detected at levels $<31 \mu \mathrm{g} / \mathrm{kg}$.

Cereal-based products $(n=15)$ comprised biscuits or breakfast cereals that were collected in local supermarkets. As highlighted for cereal samples, TeA was evidenced in most items at levels ranging from 5.2 to $628 \mu \mathrm{g} / \mathrm{kg}$. One biscuit and two breakfast cereals were found with both AOH and AME at levels $<10 \mu \mathrm{g} / \mathrm{kg}$. TEN, not a benchmarked toxin, was often found in these foods but at low levels (max. $6.9 \mu \mathrm{g} / \mathrm{kg}$ ).

Food commodities not mentioned in the EU draft recommendation were also considered to get insight about occurrence of Alternaria toxins. Fruits $(n=9)$ comprised dried fruits (apricots, raisins, and blueberries) and a single pomegranate juice. All dried fruits contained TeA at levels from 33 to $158 \mu \mathrm{g} / \mathrm{kg}$ with the exception of dried raisins. Other toxins were at $<20 \mu \mathrm{g} / \mathrm{kg}$. Wei et al. [35] already alerted about the high incidence rate of TeA (but also of AOH, AME, and TEN) in dried fruits from China (wolfberries, apricots, raisins, and figs). The pomegranate juice concentrate was contaminated by all five toxins at levels largely above those depicted in the other fruit-based items, i.e., at $17,80,48$, 13 , and $685 \mu \mathrm{g} / \mathrm{kg}$ for ALT, AOH, AME, TEN, and TeA, respectively.

To our knowledge, the presence of Alternaria toxins in cocoa (cocoa nibs, cocoa powder) and dried tea (black tea, green tea, etc.) has not been investigated previously. None of the toxins were detected in the $n=5$ cocoa items and $n=15$ tea samples surveyed at our LOQs.

From a global perspective, the data collected on these 138 samples are well aligned with the last EFSA reports. ALT was detected in one out of the 138 samples surveyed $(0.7 \%)$, confirming previous EFSA findings where only $0.6 \%$ of samples were reported positive (mainly oilseeds) [3]. It is important to mention that ALT is not cited anymore in the 2016 EFSA report [4]. On the contrary, TeA was the most often detected Alternaria toxin in this set of raw materials and finished products $(62 \%)$, and at the highest concentrations whatever the food material. Typically, paprika and chili powder were prone to contamination with levels regularly depicted above $10,000 \mu \mathrm{g} / \mathrm{kg}$. AOH, TEN, and AME toxins were detected in $33 \%, 30 \%$, and $21 \%$ of the samples with large discrepancies between commodities, for which spices, herbs, fruits juices, and cereals represented the majority of positive findings. In total, nine samples were above the still discussed EU benchmark levels, due to exceeded levels of TeA, $\mathrm{AOH}$, and/or AME in paprika samples and tomato products. It is worth mentioning that one or several Alternaria toxins were concomitantly depicted in several commodities tested, with large variability in concentrations. However, no co-occurrence trend can be extrapolated from our limited set of data.

\subsection{Occurrence of Alternaria Toxins in Green Coffee}

A summary of Alternaria toxins levels in green coffee, sorted by country of origin, is given in Table 4 (full details available in Table S1). In the large majority of samples, none of the five targeted Alternaria toxins were detected. Only seven samples ( $9 \%)$ were found positive with at least one toxin, and were from Brazil $(n=1)$, Peru $(n=1)$, Ivory Coast $(n=1)$, and Vietnam $(n=4)$. AOH was detected in four samples at levels $<3 \mu \mathrm{g} / \mathrm{kg}$. AME and TEN were each quantified in one single sample at level $<1.3 \mu \mathrm{g} / \mathrm{kg}$ and TeA in two samples (10 and $13 \mu \mathrm{g} / \mathrm{kg}$ ). ALT was not detected in any sample. 
Co-contamination at quantifiable levels was recorded in one single sample from Vietnam $(\mathrm{AOH}+$ AME, $2.98 \mu \mathrm{g} / \mathrm{kg})$.

Table 4. Occurrence of Alternaria toxins in green coffee $(n=78)$ from 21 producing countries. Range of concentrations is given in $\mu \mathrm{g} / \mathrm{kg}$ (nb of positive).

\begin{tabular}{|c|c|c|c|c|c|}
\hline $\begin{array}{l}\text { Producing Countries } \\
\text { (Nb of Samples) }\end{array}$ & ALT & $\mathrm{AOH}$ & AME & TEN & $\mathrm{TeA}$ \\
\hline Brazil (5) & $<0.5(0)$ & $<0.5(0)$ & $<0.5(0)$ & $<0.5(0)$ & $<2.5-10.0(1)$ \\
\hline Cameroon (2) & $<0.5(0)$ & $<0.5(0)$ & $<0.5(0)$ & $<0.5(0)$ & $<2.5(0)$ \\
\hline China (2) & $<0.5(0)$ & $<0.5(0)$ & $<0.5(0)$ & $<0.5(0)$ & $<2.5(0)$ \\
\hline Columbia (4) & $<0.5(0)$ & $<0.5(0)$ & $<0.5(0)$ & $<0.5(0)$ & $<2.5(0)$ \\
\hline Costa Rica (2) & $<0.5(0)$ & $<0.5(0)$ & $<0.5(0)$ & $<0.5(0)$ & $<2.5(0)$ \\
\hline Ethiopia (4) & $<0.5(0)$ & $<0.5(0)$ & $<0.5(0)$ & $<0.5(0)$ & $<2.5(0)$ \\
\hline Guatemala (2) & $<0.5(0)$ & $<0.5(0)$ & $<0.5(0)$ & $<0.5(0)$ & $<2.5(0)$ \\
\hline Honduras (4) & $<0.5(0)$ & $<0.5(0)$ & $<0.5(0)$ & $<0.5(0)$ & $<2.5(0)$ \\
\hline India (2) & $<0.5(0)$ & $<0.5(0)$ & $<0.5(0)$ & $<0.5(0)$ & $<2.5(0)$ \\
\hline Indonesia (4) & $<0.5(0)$ & $<0.5(0)$ & $<0.5(0)$ & $<0.5(0)$ & $<2.5(0)$ \\
\hline Ivory Coast (6) & $<0.5(0)$ & $<0.5-1.2(1)$ & $<0.5(0)$ & $<0.5(0)$ & $<2.5(0)$ \\
\hline Kenya (2) & $<0.5(0)$ & $<0.5(0)$ & $<0.5(0)$ & $<0.5(0)$ & $<2.5(0)$ \\
\hline Mexico (3) & $<0.5(0)$ & $<0.5(0)$ & $<0.5(0)$ & $<0.5(0)$ & $<2.5(0)$ \\
\hline Nicaragua (2) & $<0.5(0)$ & $<0.5(0)$ & $<0.5(0)$ & $<0.5(0)$ & $<2.5(0)$ \\
\hline Papua New Guinea (4) & $<0.5(0)$ & $<0.5(0)$ & $<0.5(0)$ & $<0.5(0)$ & $<2.5(0)$ \\
\hline Peru (4) & $<0.5(0)$ & $<0.5(0)$ & $<0.5(0)$ & $<0.5(0)$ & $<2.5-13.2(1)$ \\
\hline Philippines (2) & $<0.5(0)$ & $<0.5(0)$ & $<0.5(0)$ & $<0.5(0)$ & $<2.5(0)$ \\
\hline Rwanda (2) & $<0.5(0)$ & $<0.5(0)$ & $<0.5(0)$ & $<0.5(0)$ & $<2.5(0)$ \\
\hline Thailand (2) & $<0.5(0)$ & $<0.5(0)$ & $<0.5(0)$ & $<0.5(0)$ & $<2.5(0)$ \\
\hline Uganda (4) & $<0.5(0)$ & $<0.5(0)$ & $<0.5(0)$ & $<0.5(0)$ & $<2.5(0)$ \\
\hline Vietnam (16) & $<0.5(0)$ & $<0.5-1.7(3)$ & $<0.5-1.3(1)$ & $<0.5-0.5(1)$ & $<2.5(0)$ \\
\hline
\end{tabular}

Both occurrence and levels of individual Alternaria toxins in green coffee were therefore low in this study. This holds even for TeA which was the most frequently found toxin and at highest levels in the other commodities considered. Due to the very low occurrence of Alternaria toxins, a potential relation between the country of origin and contamination levels could not be investigated further.

In a previous study conducted on 85 green coffee samples from nine countries [16], AME was more frequently detected and quantified (seven samples, $8 \%$ ) at levels ranging from 0.6 to $8.3 \mu \mathrm{g} / \mathrm{kg}$. $\mathrm{AOH}$ and TEN were not seen but LOQs were much higher at that time (10 and $5 \mu \mathrm{g} / \mathrm{kg}$, respectively). TeA and ALT were not analyzed.

\subsection{Risk Assessment: Alternaria Toxins in Green Coffee}

As mentioned earlier, the five EFSA selected Alternaria toxins are not well characterized from a toxicological point of view [3]. ALT, TeA, and TEN were not found mutagenic in the in vitro bacterial Ames test $[3,36]$. No data on genotoxicity in mammalian systems are available. Thus, all of them belong to the structural Cramer class III with a TTC of $1500 \mathrm{ng} / \mathrm{kg} \mathrm{BW/d} \mathrm{[3,6].} \mathrm{On} \mathrm{the} \mathrm{contrary,}$ $\mathrm{AME}$ and $\mathrm{AOH}$ were found mutagenic in the bacterial Ames test. Only $\mathrm{AOH}$ was found genotoxic in mammalian cells in vitro. AOH was not genotoxic in the in vivo micronucleus test (bone marrow) and in the in vivo alkaline comet assay (liver), probably because systemic AOH bioavailability is very low. Local genotoxicity at the site of tissue contact (gastrointestinal tract) could not be adequately analyzed because of adverse effects of repeated corn oil gavage [37]. Based on the available data, a genotoxic/carcinogenic potential of $\mathrm{AOH}$ on the mucosa of the gastrointestinal tract can be assumed. EFSA concluded that it was appropriate to apply the TTC of $2.5 \mathrm{ng} / \mathrm{kg} \mathrm{BW} / \mathrm{d}$ for genotoxic carcinogens. Similarly, TTC for genotoxic carcinogens was applied to AME.

An adult of $60 \mathrm{~kg}$ body weight drinking five cups of coffee per day was taken as reference exposure scenario covering the majority of consumers. The manufacturing of coffee from green coffee 
comprises roasting loss, extraction into the brew, as well as processing factors for soluble coffee. Therefore, a consumption equivalent of $28 \mathrm{~g}$ of green coffee per day was considered, covering all types of coffee products.

The principal source of mycotoxins in food are usually cereals, a major staple food. The TTC refers to total intake from all potential sources. In order to avoid total dietary exposures exceeding the TTC, Alternaria toxins in coffee should contribute only to a small proportion of the total exposure. Up to $10 \%$ of the TTC as contribution by mycotoxin exposure from coffee was considered to be without safety concern. Considering the scenario exposure ( $28 \mathrm{~g} / \mathrm{d}$ green coffee), the $10 \%$ threshold level corresponds to safe levels of $0.54 \mu \mathrm{g} / \mathrm{kg}$ of AOH/AME and $320 \mu \mathrm{g} / \mathrm{kg}$ of TeA/TEN/ALT in green coffee. The LOQs achieved in this method for coffee $(0.5 \mu \mathrm{g} / \mathrm{kg}$, except TEA at $2.5 \mu \mathrm{g} / \mathrm{kg})$ are thus low enough to ensure that not quantifiable levels can a priori be considered as safe and to focus the risk assessment on positive findings.

Exposures were calculated for the highest level of each toxin analyzed which represents a worst-case scenario. AOH and AME being structurally similar, and both mutagenic and genotoxic, their toxicity is expected to be additive in case of combined exposure. In the single case of co-contamination, exposure from the sum of $\mathrm{AOH}$ and AME was compared to the TTC for genotoxic carcinogen.

As shown in Table 5, exposure to the carcinogenic $\mathrm{AOH}, \mathrm{AME}$, and $\mathrm{AOH}+\mathrm{AME}$ from coffee could represent much more than $10 \%$ of the relevant TTC whilst exposure to the non-genotoxic molecules ALT, TEN, and TeA was negligible. However, the TTC value is not a threshold to adverse effects but rather a guideline for the level of concern and based on very conservative assumptions. The true carcinogenic potency of Alternaria toxins in mammals is not known. Based on EFSA evaluation, the estimated chronic exposure to these toxins from the diet (which did not include coffee) is about $3 \times$ the TTC even on average and may be $>10 \times$ the TTC in high consumers [1,3]. Additional exposure from coffee, even with co-contamination, would not significantly increase total exposure. Perhaps most importantly, this risk assessment was performed on green coffee without considering the impact of roasting. The fate of Alternaria toxins upon coffee roasting is unknown. Published information is available essentially for Ochratoxin A, Aflatoxins, and Sterigmatocystin, for which destruction by roasting of about $80 \%, 50-60 \%$, and $70 \%$, respectively, were reported [38-41]. Such information suggests that substantial destruction of several structurally different mycotoxins occurs during roasting. Therefore, even the highest calculated exposures to Alternaria toxins from green coffee beans are not considered to represent a safety concern for consumers: they are sporadic and short-term whereas TTC refers to regular chronic exposure over a lifetime.

Table 5. Summary of occurrence of Alternaria toxins in 78 green coffee samples, and exposure from highest levels recorded.

\begin{tabular}{|c|c|c|c|c|c|c|c|c|}
\hline \multirow{2}{*}{ Toxin } & \multirow{2}{*}{$\begin{array}{c}\text { LOQ } \\
(\mu \mathrm{g} / \mathrm{kg})\end{array}$} & \multicolumn{3}{|c|}{ Number of Samples } & \multirow{2}{*}{$\begin{array}{l}\text { Max Level } \\
(\mu \mathrm{g} / \mathrm{kg})\end{array}$} & \multirow{2}{*}{$\begin{array}{c}\text { Max Exposure }{ }^{2} \\
\text { (ng/kg BW/d) }\end{array}$} & \multirow{2}{*}{$\begin{array}{c}\text { TTC (ng/kg } \\
\text { BW/d) }\end{array}$} & \multirow{2}{*}{$\%$ TTC $^{2}$} \\
\hline & & $\mathrm{ND}^{1}$ & $<$ LOQ & $>$ LOQ & & & & \\
\hline ALT & 0.5 & $78(100 \%)$ & 0 & 0 & - & - & 1500 & - \\
\hline $\mathrm{AOH}$ & 0.5 & $73(94 \%)$ & $1(1 \%)$ & $4(5 \%)$ & 2.75 & 1.3 & 2.5 & 52 \\
\hline AME & 0.5 & $71(91 \%)$ & $6(8 \%)$ & $1(1 \%)$ & 1.29 & 0.6 & 2.5 & 24 \\
\hline TEN & 0.5 & $77(99 \%)$ & 0 & $1(1 \%)$ & 0.52 & 0.2 & 1500 & 0.01 \\
\hline $\mathrm{TeA}$ & 2.5 & $75(96 \%)$ & $1(1 \%)$ & $2(3 \%)$ & 13.2 & 6.2 & 1500 & 0.4 \\
\hline $\begin{array}{c}\mathrm{AOH}+ \\
\mathrm{AME}\end{array}$ & - & - & - & - & 2.98 & 1.4 & 2.5 & 56 \\
\hline
\end{tabular}

${ }^{1}$ Not detected; ${ }^{2}$ exposure and \%TTC resulting from the highest concentration level of each toxin analyzed.

\section{Conclusions}

The underestimation of Tenuazonic acid in dry samples such as cereals and cereal-based products was reported when inappropriate extraction solvent was used as currently done in several methodologies. Such findings prompted us to develop our own isotope dilution confirmatory 
LC-MS/MS method for the analysis of five Alternaria toxins in raw materials comprising cereals, cocoa, green coffee, fruits, herbs, nuts, sunflower oils, spices, tea, and vegetables, but also in some finished products. Validation data collected in two different laboratories unambiguously demonstrated the robustness of the method.

Occurrence data on 216 samples has evidenced the presence of one or several toxins in almost all food commodities tested. Cocoa, tea, and sunflower oil seem to be less affected by Alternaria fungal species, but more data would be needed to confirm this statement. Tenuazonic acid was the most often detected Alternaria toxin, and at the highest concentrations whatever the food material. Typically, paprika and chili powder were prone to contamination with levels regularly depicted above the 10,000 $\mu \mathrm{g} / \mathrm{kg}$ EU benchmark level for paprika. Due to the lack of data available in coffee, the analysis of 78 samples of green coffee from all producing regions worldwide was included in this study. Contamination of green coffee beans by Alternaria toxins was rare and low. It is important to note that the fate of Alternaria toxins upon coffee roasting is still unknown. Our data suggest that coffee is a negligible source of exposure to Alternaria toxins and that there is no safety concern.

The wide scope of application of this analytical approach along with its adequate sample throughput at $\mu \mathrm{g} / \mathrm{kg}$ level make it fit for purpose for regular monitoring of Alternaria toxins in foods in high routine environments.

\section{Materials and Methods}

\subsection{Chemicals and Reagents}

LC gradient grade solvents (acetonitrile, methanol, n-hexane, isopropanol) and water were from Merck (Darmstadt, Germany) whereas concentrated formic acid, 25\% ammonia solution, and ammonium acetate were purchased from Sigma-Aldrich (Buchs, Switzerland). Ready-to-use QuEChERS salts containing $4 \mathrm{~g}$ of sodium sulphate $\left(\mathrm{Na}_{2} \mathrm{SO}_{4}\right)$ and $1 \mathrm{~g}$ of sodium chloride $(\mathrm{NaCl})$ were from Agilent (Geneva, Switzerland).

Alternaria toxins, namely altenuene (ALT), alternariol (AOH), alternariol monomethyl ether (AME), tentoxin (TEN), and tenuazonic acid (TeA) were obtained from ASCA GmbH (Berlin, Germany). Related isotopically labeled standards, which are ${ }^{2} \mathrm{H}_{6}$-Altenuene (ALT-IS), ${ }^{2} \mathrm{H}_{3}$-Alternariol (AOH-IS), ${ }^{2} \mathrm{H}_{3}$-Alternariol monomethylether (AME-IS), ${ }^{2} \mathrm{H}_{3}$-Tentoxin (TEN-IS), and ${ }^{13} \mathrm{C}_{2}$-tenuazonic acid (TeA-IS) were from ASCA GmbH as well, each with chemical purity $>99 \%$ and isotopic purity $>97 \%$.

\subsection{Preparation of Standard Solutions}

Stock standard solutions of each unlabeled and labeled toxin were prepared at $100 \mu \mathrm{g} / \mathrm{mL}$ in methanol. Composite working solutions of unlabeled standards were then obtained by successive dilutions at $1(\mathrm{TeA}$ at $5 \mu \mathrm{g} / \mathrm{mL})$ and $0.1 \mu \mathrm{g} / \mathrm{mL}(\mathrm{TeA} 0.5 \mu \mathrm{g} / \mathrm{mL})$ using water methanol $(80+20)$ as solvent mixture. A composite working solution of the internal standards (ISs) was prepared at $1 \mu \mathrm{g} / \mathrm{mL}$ $\left(5 \mu \mathrm{g} / \mathrm{mL}\right.$ for TeA-IS) in methanol. All solutions were stored at $-20^{\circ} \mathrm{C}$ and attained room temperature (RT) before use.

\subsection{Sample Collection}

Food raw materials $(n=116)$ were collected from own facilities and comprised nuts $(13)$, dried fruits or fruit juice concentrate (9), sunflower oils (4), herbs (11), spices (21), cocoa (5), vegetables (11), tea (15), and cereals (27). Commercially available foodstuffs $(n=22)$ were purchased from local supermarkets in Switzerland and were cereal-based products (breakfast cereals (8), biscuits (7)), rice (4), and tomato products (3; puree, ketchup, and dried).

In addition, green coffee samples $(n=78)$ were obtained from suppliers located in 21 producing countries which are Vietnam, Ivory Coast, Brazil, Colombia, Ethiopia, Honduras, Indonesia, Papua New Guinea, Peru, Uganda, Mexico, Cameroon, China, Costa Rica, Guatemala, India, Kenya, Nicaragua, Philippines, Rwanda, and Thailand. 
When the sample was not in powdered form with homogeneity visually not sufficient, intensive comminution (at least $100 \mathrm{~g}$ ) was performed using a cryogenic grinder (SPEX 6875D Freezer/Mill, Stanmore, UK) and the ground sample kept in an air-tight container at $-20{ }^{\circ} \mathrm{C}$ until analysis.

\subsection{Sample Extraction Methodology}

The finely ground test portion or oil ( $5 \mathrm{~g}$ for cereals and cereal-based products and green coffee, $2.5 \mathrm{~g}$ for tree nuts, dried fruits, cocoa, vegetables included tomato-based products, and vegetable oils, or $0.5 \mathrm{~g}$ for spices, herbs, and tea) was weighed into a $50-\mathrm{mL}$ polypropylene tube (Becton Dickinson, Le Pont de Claix, France) to which $50 \mu \mathrm{L}$ of the composite IS working solution at $1 \mu \mathrm{g} / \mathrm{mL}(5 \mu \mathrm{g} / \mathrm{mL}$ for TeA-IS) was added. The IS fortified sample was thoroughly mixed on a vortex to ensure that the spiked volume was totally absorbed by the matrix. Water $(10 \mathrm{~mL}$ ) and a ceramic homogenizer (Agilent, Geneva, Switzerland) were added and the tube vigorously shaken until no lumps were present. Acetonitrile containing $0.1 \%$ concentrated formic acid $(10 \mathrm{~mL})$ was then added and the mixture shaken using a mechanical shaker (SPEX SamplePrep GenoGrinder, Stanmore, UK) at $1500 \mathrm{rpm}$ for 3 min. QuEChERS salts ( $5 \mathrm{~g}$ ) were supplemented to the slurry which was shaken again using the GenoGrinder shaker (1500 rpm, $3 \mathrm{~min}$ ). After centrifugation at $4000 \times g$ for $10 \mathrm{~min}$ at room temperature (Heraeus Multifuge, Thermo Fisher Scientific, Bremen, Germany), the supernatant ( $5 \mathrm{~mL}$ ) was transferred into a $15-\mathrm{mL}$ polypropylene tube to which hexane $(5 \mathrm{~mL})$ was added for defatting purpose. The mixture was first mechanically shaken (GenoGrinder $1500 \mathrm{rpm}, 3 \mathrm{~min}$ ), then centrifuged (4000× $g, 1 \mathrm{~min})$. The upper hexane phase was discarded and the lower phase $(1 \mathrm{~mL})$ transferred into a new 15-mL polypropylene tube. After evaporation to dryness under a stream of nitrogen at $40{ }^{\circ} \mathrm{C}$, the residue was resuspended in water:methanol $(80+20,0.5 \mathrm{~mL})$ by vortexing $(5 \mathrm{~s})$ and sonication $(3 \mathrm{~min})$, and eventually centrifuged at $13,000 \times g$ at room temperature for 10 min using a benchtop centrifuge (Heraeus Frisco 17, Thermo Scientific). If still cloudy, the supernatant was filtered by means of a hydrophilic PTFE $0.20 \mu \mathrm{m}$ syringe filter (Millex-LG, Sigma-Aldrich). The final extract was collected into a HPLC amber glass vial for further LC-MS/MS analysis.

Initial trials were performed using the method developed for the MLT. In that case, the finely ground test portion $(2 \mathrm{~g})$ was extracted with $15 \mathrm{~mL}$ of methanol/water/acetic acid (85/14/1, v/v/v) mixture. After shaking (45 min) and centrifugation $(10 \mathrm{~min}, 4000 \times \mathrm{g})$, the supernatant $(7.5 \mathrm{~mL}$, equivalent to $1.0 \mathrm{~g}$ sample) was diluted with an equal volume of $1 \%(v / v)$ aqueous acetic acid solution before being purified on a polymeric solid-phase extraction (SPE) cartridge (Phenomenex Strata-XL, 6 cc, 200 mg). After evaporation $(7 \mathrm{~mL})$, the extract was first reconstituted with $400 \mu \mathrm{L}$ of methanol, extensively vortexed for $20 \mathrm{~s}$, and completed with $600 \mu \mathrm{L}$ of a $5 \mathrm{mM}$ ammonium acetate buffer ( $\mathrm{pH}$ 8.0). After filtration using a PTFE syringe filter (Millex-LG), the sample was injected onto a LC-MS/MS instrument.

\subsection{LC-MS/MS Methodology}

Liquid chromatography was performed on an Agilent 1290 Infinity system (Geneva, Switzerland) using a VanGuard BEH C18 pre-column $(2.1 \times 5 \mathrm{~mm}, 1.7 \mu \mathrm{m})$ attached to a Acquity UPLC BEH C18 column $(2.1 \times 100 \mathrm{~mm}, 1.7 \mu \mathrm{m})$, both from Waters Corporation (Milford, MA, USA) and thermostated at $50{ }^{\circ} \mathrm{C}$. Mobile phases were composed of ammonium acetate $5 \mathrm{mM}$ in water $\mathrm{pH} 8$ (solvent $\mathrm{A}$ ) and methanol (solvent B). A gradient program was set up as follows: 0-0.2 min with 95\% A; 0.2-2 min linear gradient down to $50 \% \mathrm{~A} ; 2-6 \mathrm{~min}$ linear gradient down to $0 \% \mathrm{~A}$, hold at $0 \% \mathrm{~A}$ for $2.5 \mathrm{~min}$; return to $95 \% \mathrm{~A}$ in $0.1 \mathrm{~min}$ and hold at $95 \% \mathrm{~A}$ for $2.4 \mathrm{~min}$ (total run time $11 \mathrm{~min}$ ). Injection volume was $5 \mu \mathrm{L}$ and the autosampler temperature was set at $8{ }^{\circ} \mathrm{C}$. The $0.4 \mathrm{~mL} / \mathrm{min}$ flow was directed into the MS detector between 1.5 and $6.5 \mathrm{~min}$ using a diverter valve. MS detection was performed using Sciex TRIPLE QUAD $6500+$ instruments (Foster City, CA, USA) equipped with a Turbo V VM Ion Source. MS parameters were obtained in negative electrospray ionization (ESI) mode by separately syringe-infusing each individual standard solution at $0.1 \mu \mathrm{g} / \mathrm{mL}$ (syringe flow rate of $10 \mu \mathrm{L} / \mathrm{min}$ ) along with the LC flow at $0.4 \mathrm{~mL} / \mathrm{min}$ using a T connector. The LC flow was constituted of $50 \%$ aqueous mobile phase A and $50 \%$ organic mobile phase B. The block source temperature was maintained at $550{ }^{\circ} \mathrm{C}$ and gas values were set as 
follows: curtain gas 40 psi, GS1 50 psi, GS2 50 psi, and collision-activated dissociation (CAD) gas pressure set as medium. Other parameters were ion spray voltage $(-3.5 \mathrm{kV})$, settling time $(15 \mathrm{~ms})$, pause between mass range $(5 \mathrm{~ms})$ entrance potential $(10 \mathrm{~V})$, collision exit potential $(15 \mathrm{~V})$. Acquisition was performed using tandem MS in scheduled selected reaction monitoring mode (Scheduled MRM ${ }^{\mathrm{TM}}$ algorithm) by monitoring two transition reactions per compound with an acquisition window of $60 \mathrm{~s}$ and a target scan time of $250 \mathrm{~ms}$. Declustering potentials (DP) and collision energies (CE) along with the respective transition reactions and retention time (RT) of each analyte are shown in Table 6. Data acquisition was carried out using Analyst software 1.5.2 and subsequent data processing done using Multiquant software 3.0 (both from Sciex, Foster City, CA, USA).

Table 6. MS/MS parameters for Alternaria toxins in negative electrospray ionization (ESI) mode (collision energy for each transition reaction is given in brackets).

\begin{tabular}{cccccc}
\hline Analyte & RT (min) & DP $($ V) & Quantification $(\mathbf{m} / z)$ & Confirmation $(\boldsymbol{m} / \mathbf{z})$ & Peak Area Ratio \\
\hline ALT & 3.45 & -60 & $291.0>214.1(-30)$ & $291.0>186.1(-35)$ & 0.66 \\
ALT-IS & 3.45 & -45 & $297.0>217.2(-30)$ & $297.0>189.0(-38)$ & 0.77 \\
AOH & 3.80 & -60 & $257.0>215.1(-35)$ & $257.0>212.0(-40)$ & 0.60 \\
AOH-IS & 3.80 & -65 & $260.0>218.0(-35)$ & $260.0>215.1(-40)$ & 0.94 \\
AME & 4.95 & -60 & $271.0>256.0(-30)$ & $271.0>228.0(-40)$ & 0.27 \\
AME-IS & 4.95 & -60 & $274.0>259.0(-30)$ & $274.0>231.1(-40)$ & 0.30 \\
TEN & 4.25 & -40 & $413.2>141.0(-25)$ & $413.2>271.0(-22)$ & 0.69 \\
TEN-IS & 4.25 & -45 & $416.2>141.0(-27)$ & $416.2>274.1(-23)$ & 0.67 \\
TeA & 2.05 & -40 & $196.1>139.1(-25)$ & $196.1>112.1(-30)$ & 0.74 \\
TeA-IS & 2.05 & -45 & $198.1>141.0(-25)$ & $198.1>114.0(-32)$ & 0.79 \\
\hline
\end{tabular}

\subsection{Identification Criteria}

Analytes were considered as positively identified when the following criteria were met simultaneously [33]: (1) a signal visible at the two diagnostic transition reactions monitored for each compound as well as at those of the related internal standard; (2) the retention time of each analyte and each internal standard in the sample extract corresponds to that of the average of the calibration solutions measured in the same sequence with a tolerance of $\pm 0.1 \mathrm{~min}$; (3) the peak area ratio from the different transition reactions recorded for each analyte in the sample extract corresponds to that of the average of the calibration solutions measured in the same sequence with a tolerance of $\pm 30 \%$. Transitions reactions monitored as well as peak area ratio tolerances are given in Table 6.

\subsection{Quantification}

Alternaria toxins were quantified by isotopic dilution using seven calibration levels ranging from 0 to $100 \mathrm{ng} / \mathrm{mL}$ (0-500 ng/mL for TeA) in water:methanol (80:20) (each level containing internal standard at $10 \mathrm{ng} / \mathrm{mL}$ for ALT, AOH, TEN, AME and $50 \mathrm{ng} / \mathrm{mL}$ for TeA). An extended calibration curve was applied for TeA in contaminated samples by adding two more calibration levels (1000 and $2000 \mathrm{ng} / \mathrm{mL}$ ).

A graph "analyte/IS area ratio" on the $y$-axis versus "analyte/IS concentration ratio" on the $x$-axis was plotted for each analyte. A $1 / x$ weighing factor was used to improve precision at the lowest calibration points. Linearity of responses was ensured by checking that the regression coefficient $\mathrm{R}^{2}$ was higher than 0.98 and that the deviation of the back-calculated concentration of the calibrants standards from the true concentration was not more than $\pm 20 \%$ [33].

The final equation to express each analyte (in $\mu \mathrm{g} / \mathrm{kg}$ ) was as follows:

$$
W=\frac{\left(\frac{A_{a}}{A_{I S}}\right)-I}{S} \times \frac{m_{I S}}{m_{a}}
$$

where $A_{a}$ is the peak area of the analyte in the sample; $A_{I S}$ is the peak area of the internal standard in the sample; $I$ and $S$ are the intercept and slope of the regression line, respectively; $m_{I S}$ is the mass of 
internal standard added to the test portion in ng (i.e., $50 \mathrm{ng}$ for ALT-IS, AOH-IS, AME-IS, TEN-IS and $250 \mathrm{ng}$ for TeA-IS); $m_{a}$ is the mass of the test portion in $\mathrm{g}$ (i.e., $5,2.5$, or $0.5 \mathrm{~g}$ ).

\subsection{Method Validation}

Two laboratories were involved in this study and were equipped with the same instrumentation. Laboratory 1 (Switzerland) developed and extensively validated the method whilst Laboratory 2 (Singapore) performed a method verification using the developed protocol without any modifications.

Validation was performed following SANTE/12682/2019 guidelines [33]. Precision data were collected on six different samples representative of each of the six commodity groups (cereal-based products, tomato-based products, tree nuts, vegetable oils, dried fruits, and spices) at one or two fortification levels. Two operators were involved in these experiments, each performing two replicates at the mentioned fortification levels over six different days (leading to a total of 12 separate experiments for each fortification level). Non-fortified samples were also analyzed in duplicate to check for any potential occurrence. For naturally contaminated samples, the native concentration obtained from unspiked samples was tentatively subtracted from the spiked values obtained.

Recovery, repeatability $\mathrm{SD}(\mathrm{r})$, and intermediate reproducibility $\mathrm{SD}(\mathrm{iR})$ precision data were calculated according to the ISO 5725-2 document [42]. Recovery values at the fortified concentrations were calculated from the median of spiked experiments performed under iR conditions. The overall uncertainty at each fortification level was obtained by combining precision and recovery contributions [43]:

$$
U(\%)=2 \times \sqrt{R S D(i R)^{2}+R S D(R e c)^{2}}
$$

where $U(\%)$ is the expanded uncertainty at the $95 \%$ confidence interval; $R S D(i R)$ is the relative standard deviation of intermediate reproducibility and $R S D(R e c)$ is the relative standard deviation of recovery.

Limits of quantification (LOQs) were set at the lowest validated fortification levels.

The stability of each individual stock standard solution prepared in $\mathrm{MeOH}$ (at $100 \mu \mathrm{g} / \mathrm{mL}$ ) was checked over 1 year when stored at $-20^{\circ} \mathrm{C}$. Each solution was compared to freshly prepared stock standard solutions. The overtime stability of sample extracts was assessed by re-injecting a series of sample extracts, prepared in duplicates, and spiked at two levels, (breakfast cereal, tomato pulp, and chili powder) previously left on the autosampler at $8{ }^{\circ} \mathrm{C}$ for 4 days.

Applicability of the method was further demonstrated on a larger range of samples (cocoa, green coffee, herbs, and tea): each sample was fortified at the LOQ and analyzed in duplicate. RSD (\%) and recovery $(\%)$ were assessed.

Method performance characteristics were verified by Laboratory 2 at one fortification level (corresponding to method LOQs) for four commodity groups (cereal-based products, tomato-based products, vegetable oil, and spice). Three operators were involved, each performing two replicates per fortification level on two occasions (leading to a total of 12 separate experiments for each fortification level).

Supplementary Materials: The following are available online at http://www.mdpi.com/2072-6651/12/9/595/s1, Table S1: Individual levels of Alternaria toxins in 216 samples.

Author Contributions: Conceptualization, P.M. and T.B.; Formal analysis, C.M. and M.-C.S.; Investigation, C.M. and M.-C.S.; Methodology, C.M. and M.-C.S.; Project administration, T.B.; Resources, P.M.; Supervision, P.M. and T.B.; Validation, Q.B., P.M.W. and E.C.Y.E.; Writing-original draft, C.M. and T.B.; Writing-review and editing, C.M., M.-C.S., Q.B. and P.M. All authors have read and agreed to the published version of the manuscript.

Funding: This research received no external funding.

Acknowledgments: The authors want to warmly thank Irene Perrin and Alain Pittet for their significant contribution in the preparation of this study, and wish them a happy, healthy, and well-deserved retirement. The authors also would like to thank Thomas Stroheker for the careful reading of the risk assessment part.

Conflicts of Interest: The authors declare no conflict of interest. 


\section{References}

1. Tirado, M.C.; Clarke, R.; Jaykus, L.A.; McQuatters-Gollop, A.; Frank, J.M. Climate change and food safety: A review. Food Res. Int. 2010, 43, 1745-1765. [CrossRef]

2. Crudo, F.; Varga, E.; Aichinger, G.; Galaverna, G.; Marko, D.; Dall'Asta, C.; Dellafiora, L. Co-Occurrence and Combinatory Effects of Alternaria Mycotoxins and Other Xenobiotics of Food Origin: Current Scenario and Future Perspectives. Toxins 2019, 11, 640. [CrossRef] [PubMed]

3. EFSA. Scientific Opinion on the risks for animal and public health related to the presence of Alternaria toxins in feed and food. EFSA J. 2011, 9, 2407. [CrossRef]

4. EFSA. Dietary exposure assessment to Alternaria toxins in the European population. EFSA J. 2016, 14, e04654. [CrossRef]

5. Zwickel, T.; Klaffke, H.; Richards, K.; Rychlik, M. Development of a high performance liquid chromatography tandem mass spectrometry based analysis for the simultaneous quantification of various Alternaria toxins in wine, vegetable juices and fruit juices. J. Chromatogr. A 2016, 1455, 74-85. [CrossRef]

6. Kroes, R.; Renwick, A.G.; Cheeseman, M.; Kleiner, J.; Mangelsdorf, I.; Piersma, A.; Schilter, B.; Schlatter, J.; van Schothorst, F.; Vos, J.G.; et al. Structure-based thresholds of toxicological concern (TTC): Guidance for application to substances present at low levels in the diet. Food Chem. Toxicol. Int. J. Publ. Br. Ind. Biol. Res. Assoc. 2004, 42, 65-83. [CrossRef]

7. EFSA. Call for Data on Alternaria Toxins in Food and Feed. Available online: http://www.efsa.europa.eu/de/ data/call/160216a (accessed on 11 August 2020).

8. De Berardis, S.; De Paola, E.L.; Montevecchi, G.; Garbini, D.; Masino, F.; Antonelli, A.; Melucci, D. Determination of four Alternaria alternata mycotoxins by QuEChERS approach coupled with liquid chromatography-tandem mass spectrometry in tomato-based and fruit-based products. Food Res. Int. 2018, 106, 677-685. [CrossRef]

9. Guo, W.; Fan, K.; Nie, D.; Meng, J.; Huang, Q.; Yang, J.; Shen, Y.; Tangni, E.K.; Zhao, Z.; Wu, Y.; et al. Development of a QuEChERS-Based UHPLC-MS/MS Method for Simultaneous Determination of Six Alternaria Toxins in Grapes. Toxins 2019, 11, 87. [CrossRef]

10. Monbaliu, S.; Wu, A.; Zhang, D.; Van Peteghem, C.; De Saeger, S. Multimycotoxin UPLC-MS/MS for Tea, Herbal Infusions and the Derived Drinkable Products. J. Agric. Food Chem. 2010, 58, 12664-12671. [CrossRef]

11. López, P.; Venema, D.; de Rijk, T.; de Kok, A.; Scholten, J.M.; Mol, H.G.J.; de Nijs, M. Occurrence of Alternaria toxins in food products in The Netherlands. Food Control. 2016, 60, 196-204. [CrossRef]

12. Xing, L.; Zou, L.; Luo, R.; Wang, Y. Determination of five Alternaria toxins in wolfberry using modified QuEChERS and ultra-high performance liquid chromatography-tandem mass spectrometry. Food Chem. 2020, 311, 125975. [CrossRef] [PubMed]

13. Zhang, Y.; Li, H.; Zhang, J.; Shao, B. Determination of Alternaria toxins in drinking water by ultra-performance liquid chromatography tandem mass spectrometry. Environ. Sci. Pollut. Res. 2019, 26, 22485-22493. [CrossRef] [PubMed]

14. Gotthardt, M.; Asam, S.; Gunkel, K.; Moghaddam, A.F.; Baumann, E.; Kietz, R.; Rychlik, M. Quantitation of Six Alternaria Toxins in Infant Foods Applying Stable Isotope Labeled Standards. Front. Microbiol. 2019, 10. [CrossRef] [PubMed]

15. Gambacorta, L.; El Darra, N.; Fakhoury, R.; Logrieco, A.F.; Solfrizzo, M. Incidence and levels of Alternaria mycotoxins in spices and herbs produced worldwide and commercialized in Lebanon. Food Control. 2019, 106, 106724. [CrossRef]

16. Bessaire, T.; Perrin, I.; Tarres, A.; Bebius, A.; Reding, F.; Theurillat, V. Mycotoxins in green coffee: Occurrence and risk assessment. Food Control. 2019, 96, 59-67. [CrossRef]

17. Verstraete, F. Analytical Challenges for an Effective EU Policy on Contaminants in Food and Feed to Ensure a High Level of Animal and Human Health Protection. In Proceedings of the Recent Advances in Food Analysis 2019, Prague, Czech Republic, 5-8 November 2019.

18. Food Chemistry Institute of the Association of the German Confectionery Industry. Alternaria Toxins: Occurrence, Toxicity, Analytical Methods, Maximum Levels. Available online: https:/www.lci-koeln.de/ deutsch/veroeffentlichungen/lci-focus/alternaria-toxins-occurrence-toxicity-analytical-methods-maximumlevels (accessed on 11 August 2020). 
19. European Union. Mandate for Standardization Addressed to CEN for Methods of Analysis for Mycotoxins in Food. Available online: https://law.resource.org/pub/eu/mandates/m520.pdf (accessed on 11 August 2020).

20. Tölgyesi, Á.; Kozma, L.; Sharma, K.V. Determination of Alternaria Toxins in Sunflower Oil by Liquid Chromatography Isotope Dilution Tandem Mass Spectrometry. Molecules 2020, 25, 1685. [CrossRef]

21. PrEN 17521. Foodstuffs-Determination of Alternaria Toxins in Tomato, Wheat and Sunflower Seeds by SPE Clean-Up and HPLC-MS/MS; European Committee for Standardization: Brussels, Belgium, 2020.

22. Puntscher, H.; Kütt, M.L.; Skrinjar, P.; Mikula, H.; Podlech, J.; Fröhlich, J.; Marko, D.; Warth, B. Tracking emerging mycotoxins in food: Development of an LC-MS/MS method for free and modified Alternaria toxins. Anal. Bioanal. Chem. 2018, 410, 4481-4494. [CrossRef]

23. Puntscher, H.; Cobankovic, I.; Marko, D.; Warth, B. Quantitation of free and modified Alternaria mycotoxins in European food products by LC-MS/MS. Food Control. 2019, 102, 157-165. [CrossRef]

24. Noser, J.; Schneider, P.; Rother, M.; Schmutz, H. Determination of six Alternaria toxins with UPLC-MS/MS and their occurrence in tomatoes and tomato products from the Swiss market. Mycotoxin Res. 2011, 27, 265-271. [CrossRef]

25. Walravens, J.; Mikula, H.; Rychlik, M.; Asam, S.; Devos, T.; Njumbe Ediage, E.; Diana Di Mavungu, J.; Jacxsens, L.; Van Landschoot, A.; Vanhaecke, L.; et al. Validated UPLC-MS/MS Methods to Quantitate Free and Conjugated Alternaria Toxins in Commercially Available Tomato Products and Fruit and Vegetable Juices in Belgium. J. Agric. Food Chem. 2016, 64, 5101-5109. [CrossRef]

26. Desmarchelier, A.; Tessiot, S.; Bessaire, T.; Racault, L.; Fiorese, E.; Urbani, A.; Chan, W.C.; Cheng, P.; Mottier, P. Combining the quick, easy, cheap, effective, rugged and safe approach and clean-up by immunoaffinity column for the analysis of 15 mycotoxins by isotope dilution liquid chromatography tandem mass spectrometry. J. Chromatogr. A 2014, 1337, 75-84. [CrossRef] [PubMed]

27. Anastassiades, M.; Lehotay, S.J.; Stajnbaher, D.; Schenck, F.J. Fast and easy multiresidue method employing acetonitrile extraction/partitioning and "dispersive solid-phase extraction" for the determination of pesticide residues in produce. J. AOAC Int. 2003, 86, 412-431. [CrossRef] [PubMed]

28. Bessaire, T.; Mujahid, C.; Mottier, P.; Desmarchelier, A. Multiple Mycotoxins Determination in Food by LC-MS/MS: An International Collaborative Study. Toxins 2019, 11, 658. [CrossRef] [PubMed]

29. Desmarchelier, A.; Fan, K.; Minh Tien, M.; Savoy, M.C.; Tarres, A.; Fuger, D.; Goyon, A.; Bessaire, T.; Mottier, P. Determination of 105 antibiotic, anti-inflammatory, antiparasitic agents and tranquilizers by LC-MS/MS based on an acidic QuEChERS-like extraction. Food Addit. Contam. Part A Chem. Anal. Control Expo. Risk Assess. 2018, 35, 646-660. [CrossRef]

30. Hickert, S.; Krug, I.; Cramer, B.; Humpf, H.-U. Detection and Quantitative Analysis of the Non-cytotoxic allo-Tenuazonic Acid in Tomato Products by Stable Isotope Dilution HPLC-MS/MS. J. Agric. Food Chem. 2015, 63, 10879-10884. [CrossRef]

31. Prelle, A.; Spadaro, D.; Garibaldi, A.; Gullino, M.L. A new method for detection of five alternaria toxins in food matrices based on LC-APCI-MS. Food Chem. 2013, 140, 161-167. [CrossRef]

32. Baslé, Q.; Mujahid, C.; Bessaire, T. Application of a streamlined LC-MS/MS methodology for the determination of atropine and scopolamine in cereals from Asian and African countries. Food Addit. Contam. Part A 2020, 1-11. [CrossRef]

33. SANTE/12682/2019. Guidance Document on Analytical Quality Control and Method Validation Procedures for Pesticide Residues and Analysis in Food and Feed; European Commission Directorate General for Health and Food Safety: Brussels, Belgium, 2019.

34. Sanzani, S.M.; Gallone, T.; Garganese, F.; Caruso, A.G.; Amenduni, M.; Ippolito, A. Contamination of fresh and dried tomato by Alternaria toxins in southern Italy. Food Addit. Contam. Part A 2019, 36, 789-799. [CrossRef]

35. Wei, D.; Wang, Y.; Jiang, D.; Feng, X.; Li, J.; Wang, M. Survey of Alternaria Toxins and Other Mycotoxins in Dried Fruits in China. Toxins 2017, 9, 200. [CrossRef]

36. Schrader, T.J.; Cherry, W.; Soper, K.; Langlois, I. Further examination of the effects of nitrosylation on Alternaria alternata mycotoxin mutagenicity in vitro. Mutat. Res./Genet. Toxicol. Environ. Mutagenesis 2006, 606, 61-71. [CrossRef]

37. Schuchardt, S.; Ziemann, C.; Hansen, T. Combined toxicokinetic and in vivo genotoxicity study on Alternaria toxins. EFSA Supporting Publ. 2014, 11, 679E. [CrossRef] 
38. Blanc, M.; Pittet, A.; Muñoz-Box, R.; Viani, R. Behavior of Ochratoxin A during Green Coffee Roasting and Soluble Coffee Manufacture. J. Agric. Food Chem. 1998, 46, 673-675. [CrossRef] [PubMed]

39. Karlovsky, P.; Suman, M.; Berthiller, F.; De Meester, J.; Eisenbrand, G.; Perrin, I.; Oswald, I.P.; Speijers, G.; Chiodini, A.; Recker, T.; et al. Impact of food processing and detoxification treatments on mycotoxin contamination. Mycotoxin Res. 2016, 32, 179-205. [CrossRef] [PubMed]

40. Soliman, K.M. Incidence, Level, and Behavior of Aflatoxins during Coffee Bean Roasting and Decaffeination. J. Agric. Food Chem. 2002, 50, 7477-7481. [CrossRef]

41. EFSA Panel on Contaminants in the Food Chain. Scientific Opinion on the risk for public and animal health related to the presence of sterigmatocystin in food and feed. EFSA J. 2013, 11, 3254. [CrossRef]

42. ISO 5725-2. Accuracy (Trueness and Precision) of Measurement Methods and Results_Part 2: Basic Method for the Determination of Repeatability and Reproducibility of a Standard Measurement Method; International Organization for Standardization: Geneva, Switzerland, 1994.

43. Barwick, V.J.; Ellison, S.L.R. The evaluation of measurement uncertainty from method validation studies. Accredit. Qual. Assur. 2000, 5, 47-53. [CrossRef]

(C) 2020 by the authors. Licensee MDPI, Basel, Switzerland. This article is an open access article distributed under the terms and conditions of the Creative Commons Attribution (CC BY) license (http://creativecommons.org/licenses/by/4.0/). 